\title{
Childhood Nonspecific Abdominal Pain in Family Practice: Incidence, Associated Factors, and Management
}

\author{
Marieke J. Gieteling, $M D^{1}$ \\ Yvonne Lisman-van Leeuwen, $\mathrm{PbD}^{2}$ \\ Jobannes C. van der Wouden, $P b D^{1}$ \\ Francois G. Schellevis, $M D, P b D^{3}$ \\ Marjolein $\mathrm{Y}$. Berger, $\mathrm{MD}, \mathrm{PbD}^{2}$ \\ 'Department of General Practice, Erasmus \\ MC-University Medical Center, Rotterdam, \\ The Netherlands \\ ${ }^{2}$ Department of General Practice, Univer- \\ sity Medical Center, University of Gronin- \\ gen, Groningen, The Netherlands \\ ${ }^{3}$ NIVEL, Netherlands Institute \\ for Health Services Research, Utrecht, \\ The Netherlands
}

\begin{abstract}
PURPOSE Nonspecific abdominal pain (NSAP) is a common complaint in childhood. In specialist care, childhood NSAP is considered to be a complex and time-consuming problem, and parents are hard to reassure. Little is known about NSAP in family practice, but the impression is that family physicians consider it to be a benign syndrome needing little more than reassurance. This discrepancy calls for a better understanding of NSAP in family practice.
\end{abstract}

METHODS Data were obtained from the Second Dutch National Survey of General Practice (2001). Using registration data of 91 family practices, we identified children aged 4 to 17 years with NSAP. We calculated the incidence, and we studied factors associated with childhood NSAP, referrals, and prescriptions.

RESULTS The incidence of NSAP was 25.0 (95\% confidence interval [CI], 23.726.3) per 1,000 person years. Most children (92.7\%) with newly diagnosed $\operatorname{NSAP}(\mathrm{N}=1,480)$ consulted their doctor for this condition once or twice. Factors independently associated with NSAP were female sex (odds ratio $[\mathrm{OR}]=1.4 ; 95 \%$ $\mathrm{Cl}, 1.3-1.5)$, nongastrointestinal-nonspecific somatic symptoms (OR $=1.3 ; 95 \%$ $\mathrm{Cl}, 1.1-1.5)$, and health care use $(\mathrm{OR}=1.04 ; 95 \% \mathrm{Cl}, 1.03-1.05)$. When NSAP was diagnosed at the first visit, $3 \%$ of the patients were referred to specialist care, and $1 \%$ received additional testing. Family physicians prescribed medication in $21.3 \%$ of the visits for NSAP.

CONCLUSIONS Childhood NSAP is a common problem in family practice. Most patients visit their doctor once or twice for this problem. Family physicians use little additional testing and make few referrals in their management of childhood NSAP. Despite the lack of evidence for effectiveness, family physicians commonly prescribe medication for NSAP.

Ann Fam Med 2011;9:337-343. doi:10.1370/afm.1268.

\section{INTRODUCTION}

bdominal pain is a common complaint in children worldwide. ${ }^{1}$
Although its effect on a child's well-being is considerable, and it
leads to substantial school absenteeism, ${ }^{2}$ childhood abdominal pain is usually not associated with organic disease. ${ }^{3,4}$ In this study, we use the expression nonspecific abdominal pain (NSAP) for abdominal pain for which the physician does not suspect an organic pathologic cause. Most studies on NSAP are carried out in specialist care and include children with chronic or recurrent abdominal pain.

Little is known about childhood NSAP in family practice. In population and school-based studies, the prevalence of NSAP ranges from $4 \%$ to $10 \% .{ }^{1}$ The occurrence of NSAP in family practice has hardly been studied, nor has family physicians' management. The impression is that family physicians consider NSAP in children to be a benign disorder needing little more than reassurance of parent and child. This view, how- 
ever, contradicts the presence of psychological comorbidity, ${ }_{1}^{5-8}$ other nonspecific somatic symptoms, ${ }^{5,7,9}$ and the high prevalence of prolonged symptoms ${ }^{11}$ found in children referred to secondary and tertiary care. In specialist care, childhood NSAP is considered to be a complex and time-consuming problem, and parents of children with NSAP are found to be hard to reassure. ${ }^{11,12}$ For pediatric gastroenterologists NSAP is the most common disorder seen..$^{13}$ The discrepancy between childhood NSAP described in specialist care and that described in primary care is challenging and calls for a better understanding of this condition in family practice.

The aim of our study was to offer a primary care perspective to childhood NSAP. Using registration data from the Second Dutch National Survey of General Practice, we performed an explorative study estimating the occurrence of childhood NSAP, studying associated factors and determining family physicians' management.

\section{METHODS}

In the Netherlands, all inhabitants are registered with a family physician. A family practice is highly accessible, and the care is free. The family physician usually knows the family well. Access to a medical specialist is possible only after referral by a family physician.

The data used in the present study were derived from the Second Dutch National Survey of General Practice (DNSGP-2, conducted in 2001), ${ }_{1}^{14}$ which was designed to study morbidity in Dutch family practice. A total of 195 family physicians in 104 practices recorded for 12 consecutive months data from 394,192 registered patients (a representative $2.5 \%$ sample of the Dutch population). The study was carried out according to the Dutch legislation on privacy. All patient contacts, all referrals, and all prescriptions were registered in the patients' electronic health records (EHRs). Morbidity was coded using the International Classification of Primary Care (ICPC), ${ }^{15}$ and prescriptions were coded according to the Anatomical Therapeutic Chemical index. ${ }^{17}$

Detailed information about the study design and methods has been reported previously. ${ }^{14,17}$ To enhance consistent and complete coding, family physicians were additionally trained in coding, and the electronic patient record-based morbidity recording systems were improved with software modules that alerted the user whenever registration was insufficient. ${ }^{17}$ The accuracy of coding was studied in a vignette study at the start of the registration period..$^{18}$ The overall agreement among 161 participating family physicians and 4 ICPC coding experts for 30 written patient cases was $81 \%$, and agreement for a written patient case about nonorganic abdominal pain (ICPC code D01, generalized abdominal pain) was $85 \% .{ }^{18}$ The level of agreement indicates that the validity and consistency of coding diagnoses was adequate. Consistency and completeness of registration were checked during the data-cleaning procedure ${ }^{17}$; data from 13 practices were excluded because of poor quality of the registered data ( 8 practices) and because of failure to register referrals ( 5 practices). ${ }^{18}$

In the DNSGP-2, visits for the same health problem were clustered into 1 disease episode. ${ }^{16}$ The ICPC code of the last visit within an episode was considered to be the episode diagnosis and coded as such. For example, a patient with an episode that consisted of 2 visits for abdominal pain, in which the first visit was coded as other localized abdominal pain (D06), and the second as appendicitis (D88), the episode diagnosis was coded as appendicitis (D88) in both visits.

\section{Study Population}

To be eligible for this analysis, a child had to aged between 4 and 17 years. Age was determined at the middle of the registration year. All visits within episodes with a diagnosis of generalized abdominal pain (D01), other localized abdominal pain (D06), and irritable bowel syndrome (D93) were considered NSAP. Family physicians use these codes when they are not aware of any disorder causing the pain. A child's health problem was considered an incident case if the first visit for NSAP during the registration year was coded as a new problem and a prevalent case if the first visit was coded as a known problem.

\section{Factors Associated With Childhood Nonspecific Abdominal Pain}

Children were labeled as having a psychological problem, a social problem, or a nongastrointestinal-nonspecific symptom whenever they had made 1 or more visits coded with a corresponding ICPC code. For a psychological problem we used ICPC chapter P (psychological and psychiatric problems: for example, P01 for feeling anxious, P02 for transient stress reaction, P03 for feeling down). For a social problem we used ICPC chapter $\mathrm{Z}$ (social problems: for example, Z20 for relationship problems with parents, Z21 and Z23 for problems with disease or death of parents/family, Z24 for problems with friends, Z25 for problems with assault or violence). We considered the following codes as nongastrointestinal-nonspecific somatic symptoms: N01 for headache, pain, A01 for general/ multiple sites, A04 for general weakness/tiredness, A06 for fainting/syncope, and A11 for chest pain not otherwise specified. 


\section{Management by Family Physicians}

First, the percentage of prescriptions and referrals during visits for NSAP was compared with percentage of prescriptions and referrals during visits for other problems. Second, we analyzed additional testing, kind of referrals, and type of prescriptions in consecutive visits for NSAP of incident cases. All referrals were analyzed. Referrals could be coded to the following mental health care specialists: social worker, physiotherapist, primary care psychologist, psychotherapist, and psychiatrist.

\section{Analyses}

The incidence rate was calculated by dividing the total number of newly diagnosed cases (numerator) by the total number of person years of the population at risk (denominator). The number of person years was calculated by using the mid-time population. As the registration period was 1 year, the mid-time population was calculated by taking the mean of the number of listed patients at the beginning of the registration period and the number of listed patients at the end of the registration. Incidence rates were expressed per 1,000 person-years. The $95 \%$ confidence intervals (CIs) were computed around incidence rates assuming a Poisson distribution using Stata 11.0 (StataCorp LP, College Station, Texas). The prevalence rate was calculated with the total number of children with a visit for NSAP as numerator. We stratified the incidence rate for boys and girls by year of age.

We compared children who had NSAP with children who did not have NSAP (aged 4 to 17 years) with respect to age; sex; the number of children with psychological, social, and nongastrointestinalnonspecific symptoms; and health care use. Health care use was calculated as the number of visits for reasons other than NSAP per child per year. Using univariate logistic regression analyses, we assessed the association between the above-enumerated factors and NSAP. Factors that during univariate analysis were significantly associated with NSAP $(P<.05)$ were entered into a multivariate logistic regression analysis. The statistical package SPSS 15.0 was used for these regression analyses (SPSS Inc, Chicago, Illinois).

\section{RESULTS}

At the beginning of the registration year our study population consisted of 59,999 children aged 4 to 17 years, yielding
59,203 person-years. During the registration year 40,781 children $(68.0 \%)$ consulted their family physician (range per practice, 129-1,486, median: 349), and 1,978 children did so for NSAP (4.9\% of all consulting children). The control group consisted of 38,803 children. In total, 1,480 children consulted their family physician for the first time with NSAP. Table 1 shows the incidence and prevalence rates for NSAP in girls and boys. Of the incident cases 1,372 (92.7\%) patients consulted only once or twice for NSAP. Figure 1 shows that the incidence rate for girls peaked around 6 years and again around 15 years. The incidence rate for boys decreased by age.

\section{Factors Associated With Nonspecific Abdominal Pain}

Children with NSAP were more often girls, consulted more for psychological and social problems and nongastrointestinal-nonspecific somatic symptoms, and had more visits for other reasons (Table 2). In the

Table 1. Childhood Cases of Nonspecific
Abdominal Pain per 1,000 Person Years

\begin{tabular}{|c|c|c|c|c|}
\hline $\begin{array}{l}\text { Patient } \\
\text { Sex }\end{array}$ & $\begin{array}{l}\text { Incidence } \\
\%(95 \% \mathrm{Cl})\end{array}$ & $\mathbf{n}$ & $\begin{array}{l}\text { Prevalence } \\
\%(95 \% \mathrm{CI})\end{array}$ & $\mathbf{n}$ \\
\hline Male & $20.3(18.8-22.0)$ & 615 & $27.3(25.5-29.2)$ & 827 \\
\hline Female & $29.9(28.0-31.9)$ & 865 & $39.8(37.6-42.1)$ & 1,151 \\
\hline All & $25.0(23.7-26.3)$ & 1,480 & $33.4(32.0-34.9)$ & 1,978 \\
\hline
\end{tabular}

Figure 1. Incidence of nonspecific abdominal pain in children ages 4 to 17 years by sex in family practice.

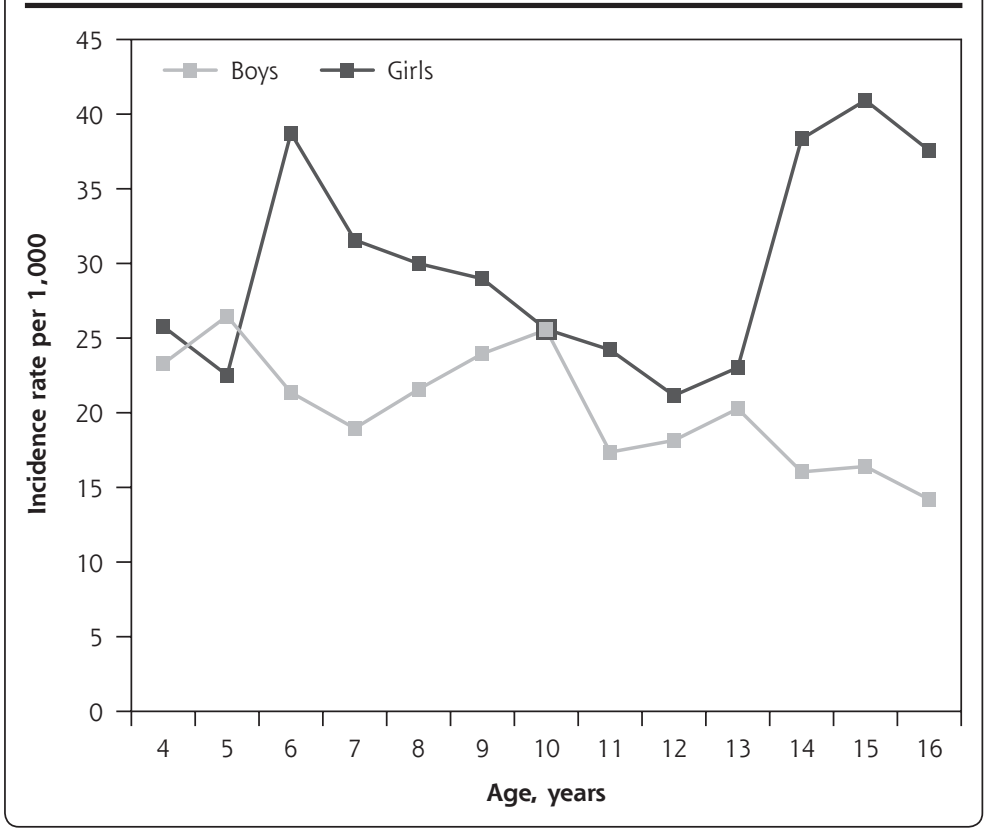


Table 2. Characteristics Associated With Childhood Nonspecific Abdominal Pain

\begin{tabular}{lcccc}
\hline Characteristic & $\begin{array}{c}\text { No NSAP } \\
(\mathbf{n}=\mathbf{3 8 , 8 0 3 )}\end{array}$ & $\begin{array}{c}\text { NSAP } \\
\mathbf{( n = 1 , 9 7 8 )}\end{array}$ & $\begin{array}{c}\text { Univariate } \\
\text { OR (95\% Cl) }\end{array}$ & $\begin{array}{c}\text { Multivariate } \\
\text { OR (95\% Cl) }\end{array}$ \\
\hline Age, mean (SD), y & $10.4(3.8)$ & $10.4(3.8)$ & $1.0(0.99-1.01)$ & - \\
Female, \% & 49.4 & 58.2 & $1.4(1.3-1.6)$ & $1.4(1.3-1.5)^{\mathrm{a}}$ \\
Psychological problem, \% & 6.6 & 6.9 & $1.1(0.9-1.3)$ & - \\
Social problem, \% & 0.8 & 1.3 & $1.6(1.1-2.4)$ & $1.4(0.9-2.1)$ \\
Nongastrointestinal-nonspecific symptoms, \% & 5.0 & 7.2 & $1.5(1.2-1.8)$ & $1.3(1.1-1.5)^{\mathrm{a}}$ \\
Health care use, visits, mean (SD), No. & $3.9(3.9)$ & $4.6(4.7)$ & $1.05(1.04-1.06)$ & $1.04(1.03-1.05)^{\mathrm{a}}$ \\
\hline
\end{tabular}

NSAP = nonspecific abdominal pain; OR = odds ratio.

Note: Reference category for each row is children without NSAP.

a $P<.05$. Logistic regression analyses was used to test the association.

\section{Table 3. Family Physician Management of Nonspecific Abdominal Pain in Children}

\begin{tabular}{lcc}
\hline Management & $\begin{array}{c}\text { NSAP } \\
(\mathbf{n}=\mathbf{2} \text { 632) }\end{array}$ & $\begin{array}{c}\text { Other Problems } \\
(\mathbf{n}=\mathbf{1 5 6} \text { 048) }\end{array}$ \\
\hline $\begin{array}{l}\text { No prescription, } \\
\text { no referral, \% }\end{array}$ & 73.7 & $49.7^{\mathrm{a}}$ \\
Prescription, \% & 21.3 & $45.3^{\mathrm{a}}$ \\
Referral, \% & 5.0 & $5.1^{\mathrm{b}}$ \\
\hline
\end{tabular}

NSAP $=$ nonspecific abdominal pain

a $P<.01$, calculated using Pearson $\chi^{2}$ test.

b $P<.05$, calculated using Pearson $\chi^{2}$ test.

multivariate analysis female sex, health care use, and nongastrointestinal-nonspecific somatic symptoms were independently associated with NSAP.

\section{Management by Family Physicians}

Family physicians referred in $5.0 \%$ of the visits for NSAP. This percentage was comparable to that with visits for other problems $(5.1 \%$; Table 3$)$. During the first visit of new patients, family physicians referred $3.0 \%$ to secondary care and ordered additional testing for $1.1 \%$ of these patients $(n=16$; Table 4$)$. The percentage of visits with a referral increased during the second visit to $5.6 \%$, but decreased again and stabilized during the third and subsequent visits (2.7\%). Most children who were referred were so at their first visit (cumulative percentage, 65.2\%). During the first visit $39.3 \%$ of the referred children were referred to a surgeon $(\mathrm{n}=24)_{\text {; }}$ in later visits most of the children were referred to a pediatrician. Only 1 child was referred to a psychiatrist.

In $21.3 \%$ of the visits for NSAP, family physicians prescribed medication at a rate that was significantly less than they prescribed medications in visits for other reasons $(45.3 \%, P<.001)$ (Table 4$)$. During subsequent visits for NSAP, the prescription rate increased (from $17.6 \%$ to $40.8 \%$ ). Approximately onethird of the total number of prescriptions were laxa-

\section{Table 4. Family Physicians' Management During Consecutive Visits for Incident Cases of Nonspecific Abdominal Pain}

\begin{tabular}{|c|c|c|c|}
\hline Management & $\begin{array}{c}\text { 1st Visit } \\
(n=1,480)\end{array}$ & $\begin{array}{l}\text { 2nd Visit } \\
(n=324)\end{array}$ & $\begin{array}{l}\geq 3 \text { Visits } \\
(n=184)\end{array}$ \\
\hline Prescription, No. (\%) & $260(17.6)$ & $90(27.8)$ & $75(40.8)$ \\
\hline $\begin{array}{l}\text { Drugs for acid- } \\
\text { related } \\
\text { disorders, \%a }\end{array}$ & 13.1 & 4.4 & 1.3 \\
\hline Antispasmodics, $\%^{\mathrm{a}}$ & 29.2 & 26.7 & 24.0 \\
\hline Laxatives, \%a & 25.0 & 32.2 & 37.3 \\
\hline \multirow{2}{*}{$\begin{array}{l}\text { Osmotic laxatives } \\
\text { (lactulose), \% }\end{array}$} & 11.2 & 15.6 & 10 \\
\hline & 12.7 & 14.4 & 14.0 \\
\hline $\begin{array}{l}\text { Bulking agents } \\
\text { (psyllium), } \%^{\mathrm{a}}\end{array}$ & 1.2 & 2.0 & 4.0 \\
\hline \multicolumn{4}{|l|}{ Others, \%a } \\
\hline $\begin{array}{l}\text { Painkillers } \\
\text { NSAIDs, \% }\end{array}$ & 5.4 & 14.4 & 14.7 \\
\hline $\begin{array}{l}\text { Painkillers } \\
\quad \text { Analgesics, \%a }\end{array}$ & 3.8 & 4.4 & 5.3 \\
\hline $\begin{array}{l}\text { Anti-infective } \\
\text { agents, \%a }\end{array}$ & 6.9 & 5.6 & 1.3 \\
\hline $\begin{array}{l}\text { Additional testing, } \\
\text { No. }(\%)\end{array}$ & $16(1.1)$ & $9(2.8)$ & 0 \\
\hline Referral, No. (\%) & $45(3.0)$ & $19(5.6)$ & $5(2.7)$ \\
\hline Pediatrician & 5 & 8 & 3 \\
\hline Surgeon & 24 & 2 & 0 \\
\hline Radiology & 0 & 1 & 0 \\
\hline Psychiatrist & 1 & 0 & 0 \\
\hline Gynecologist & 2 & 1 & 1 \\
\hline Cardiologist & 1 & 1 & 0 \\
\hline Urologist & 0 & 1 & 0 \\
\hline Physiotherapist & 2 & 2 & 0 \\
\hline Dietician & 2 & 1 & 0 \\
\hline Unknown & 2 & 1 & 1 \\
\hline Other & 6 & 1 & 0 \\
\hline
\end{tabular}

tives, $(25.0 \%$ to $37.3 \%)$ and another one-third were antispasmodics (24.0\% to $29.2 \%)$. Family physicians did not prescribe antidepressants or benzodiazepine derivatives for NSAP. 


\section{DISCUSSION}

With an incidence rate of 25.0 per 1,000 person years (95\% CI, 23.7-26.3) NSAP is one of the 10 most commonly seen complaints of children in Dutch family practice. ${ }^{15}$ Annually, a Dutch family physician with a practice of average size will see approximately 21 children aged 4 to 17 years with NSAP. Only a few (less than $7 \%$ ) new patients with NSAP consult more than twice for this problem. In the present study, female sex, health care use, and other nongastrointestinal-nonspecific somatic symptoms were independently associated with NSAP. Family physicians referred in $5.0 \%$ of the visits for NSAP and prescribed medication in $21.3 \%$.

The results of the present study show that childhood NSAP is a common problem in family practice. It is therefore remarkable that it has rarely been studied in this setting. We are aware of only one study that reported the frequency of visits for NSAP in primary care. In Australia, 1.4 of every 100 visits of children and adolescents aged 0 to 24 years were due to NSAP. ${ }^{19}$

In the present study, the incidence of girls consulting for NSAP showed 2 age peaks, and for boys the incidence decreased by age. The incidence rate for NSAP in family practice has not been reported before. Open-population studies have reported a prevalence rate of childhood chronic or recurrent abdominal pain by age. ${ }^{3,20,21}$ All studies show a peak in the occurrence of NSAP around 3-6 years of age. Although not studied yet, explanations for this age peak might be school attendance and its associated anxieties. The observed age peak of 12 to 16 years for girls in our study might be explained by menarche or dysmenorrhea.

In the medical literature a variety of expressions are used for childhood nonorganic abdominal pain: recurrent abdominal pain $i^{1,3,20,22}$ chronic abdominal pain ${ }_{i}^{23,24}$ functional abdominal pain ${ }_{i}^{25}$ and nonspecific abdominal pain. ${ }^{26,27}$ Most of these terms include a minimal duration of abdominal pain, usually 3 months. This time criterion was arbitrarily set by Apley et al, who were the first to describe the pain syndrome in $1958 .^{3}$ The time criterion was meant to reduce the risk of organic causes, because they will usually become manifest with time. The extent of additional testing for organic abnormalities differs among studies. Because of its comparable origin, ie, a nonorganic cause, we consider NSAP in family practice as a poorly studied part of the spectrum of the same pain syndrome.

Although in referred children it has been repeatedly found that chronic or recurrent abdominal pain is associated with psychological symptoms, ${ }^{5-9}$ Dutch family physicians did not associate childhood NSAP with psychological and social problems. We believe that family physicians almost certainly ask for psycho- social complaints in visits for childhood NSAP, but that they probably regarded these complaints as being too mild to code them using ICPC. Our finding gives room for speculation about whether the association found in referred children might be biased because of selective referral of children with NSAP and (severe) psychosocial problems. On the other hand, it has also been reported that family physicians have difficulty identifying psychological problems in children. ${ }^{28-30}$

Given the low percentages of additional testing and referrals, we assume that family physicians feel comfortable labeling childhood abdominal pain as NSAP, or nonorganic abdominal pain. That the physicians did not refer to a pediatric gastroenterologist (ie, for endoscopy) is the result of a 2-step procedure used in the Netherlands. A Dutch family physician will refer a child to a general pediatrician, who will refer to a pediatric gastroenterologist, if indicated. Few children revisited their family physician more than twice for NSAP. These findings are remarkable, because in referred children it has been shown that NSAP has a chronic course, ${ }^{10}$ and parents are found to be demanding and difficult to reassure. ${ }^{11,12}$ Maybe the family physicians successfully managed early stages of NSAP. That is the family physician reassured the child and parents that there were no severe underlying disorders and taught families how to deal with the abdominal pain of the child. This style may promote a self-limited outcome for common symptoms. If so, this finding supports the cost effectiveness of primary care. ${ }^{31}$

In contrast, however, we do not know whether the children who did not revisit would be free of abdominal pain or were able to cope with their abdominal pain. It has been reported that children look for help elsewhere, eg, complementary therapy and homeopathic products. ${ }^{32,33}$ Future research should further explore the prognosis of NSAP in family practice and the effect of the management of the family physician.

With respect to treatment, family physicians do not adhere to published evidence. Despite the lack of evidence for a positive effect of any medication in NSAP, ${ }^{34}$ in $21 \%$ of the visits physicians prescribed medication (predominantly laxatives and antispasmodics). They seemed to believe that laxatives are effective in NSAP or they hesitated between a diagnosis NSAP and constipation. The effectiveness of laxatives for NSAP is not supported by clinical evidence ${ }^{34,35}$ and should be studied first. In contrast to others, Dutch family physicians did not prescribe anxiolytics or antidepressants to children with NSAP. ${ }^{36}$

\section{Study Limitations}

A limitation of our study is its dependence on the quality of the EHR registration by the family physicians. 
We believe, however, that the data give an accurate picture of childhood NSAP in family practice. In the Netherlands all family physicians electronically register health records and code morbidity using ICPC codes. The DNSGP-2 was set up to study morbidity in family practice, and the family physicians participating in the DNSGP-2 study were additionally trained in coding. Completeness of registration was assured by excluding family practices with poor registration..$^{17,18}$ The content validity control of coding was restricted by a vignette study at the start of the registration period. The vignette study showed an adequate accuracy and consistency of coding with ICPC. ${ }^{18}$ The validity of individual patient records, however, has not been assessed in the DNSGP-2. The ICPC codes registered represent daily practice in family practice. ICPC codes were not compared with a reference standard. For the nonspecific symptom codes we use in our analysis, however, there is no reference standard. A systematic review recently has shown that the reliability of the diagnoses of a general practice research database very comparable to ours is good. ${ }^{37}$

There is always, however, a chance of misclassifying organic abdominal pain as nonorganic NSAP. This risk may be higher for diseases that lack an official ICPC code, such as NSAP. We assume family physicians code NSAP with the existing ICPC codes that describe abdominal pain without mentioning a specific organic abnormality. This assumption was based on our own clinical experience with ICPC and on the observation that $85 \%$ of the participating physicians $(\mathrm{n}=161)$ coded a written patient case regarding NSAP with ICPC D01 (generalized abdominal pain). ${ }^{18}$ In addition, to reduce misclassification, we selected our cases by using the final diagnosis of a health problem. At the end of a health problem (a cluster of visits concerning the same complaint), the diagnostic process is completed and time has passed; therefore, at the end of a health problem, the uncertainty about the cause of abdominal pain is modest.

Another drawback of this health record registration database was that it was not possible to explore prognosis or duration of abdominal pain. We looked at children visiting for abdominal pain and found that most children visited only once or twice for this complaint. We do, however, not know that the children who did not contact more often were not suffering from abdominal pain. Recently our study group showed that $47 \%$ of children consulting a family practice with a new episode of abdominal pain had chronic complaints (3 or more months of abdominal pain) at first presentation. ${ }^{38}$ We feel we studied the same pain syndrome as previously reported from studies on recurrent or chronic abdominal pain. The differences with other studies is the time-frame studied and the probability of a nonorganic disorder.

Childhood NSAP is a common complaint in family practice. Less than $7 \%$ of children with NSAP diagnosed visit more than twice for this problem. Family physicians diagnose NSAP by using few additional tests and few referrals. Despite the lack of evidence for effectiveness, family physicians frequently prescribe laxatives and antispasmodics for childhood NSAP.

To read or post commentaries in response to this article, see it online at http://www.annfammed.org/cgi/content/full/9/4/337.

Key words: Abdominal pain; nonspecific somatic symptoms; management; children and adolescents

Submitted August 23, 2010; submitted, revised, March 9, 2011; accepted March 15, 2011.

\section{References}

1. Chitkara DK, Rawat DJ, Talley NJ. The epidemiology of childhood recurrent abdominal pain in Western countries: a systematic review. Am J Gastroenterol. 2005;100(8):1868-1875.

2. Youssef NN, Murphy TG, Langseder AL, Rosh JR. Quality of life for children with functional abdominal pain: a comparison study of patients' and parents' perceptions. Pediatrics. 2006;117(1):54-59

3. Apley J, Naish N. Recurrent abdominal pains: a field survey of 1,000 school children. Arch Dis Child. 1958;33(168):165-170.

4. Størdal K, Nygaard EA, Bentsen BS. Organic abnormalities in recurrent abdominal pain in children. Acta Paediatr. 2001;90(6):638-642.

5. Dufton LM, Dunn MJ, Compas BE. Anxiety and somatic complaints in children with recurrent abdominal pain and anxiety disorders. J Pediatr Psychol. 2009;34(2):176-186.

6. Kaminsky L, Robertson M, Dewey D. Psychological correlates of depression in children with recurrent abdominal pain. J Pediatr Psychol. 2006;31(9):956-966.

7. Dorn LD, Campo JC, Thato S, et al. Psychological comorbidity and stress reactivity in children and adolescents with recurrent abdominal pain and anxiety disorders. J Am Acad Child Adolesc Psychiatry. 2003;42(1):66-75.

8. Garber J, Zeman J, Walker LS. Recurrent abdominal pain in children: psychiatric diagnoses and parental psychopathology. J Am Acad Child Adolesc Psychiatry. 1990;29(4):648-656.

9. Compas BE, Boyer MC, Stanger C, et al. Latent variable analysis of coping, anxiety/depression, and somatic symptoms in adolescents with chronic pain. J Consult Clin Psychol. 2006;74(6):1132-1142.

10. Gieteling MJ, Bierma-Zeinstra SM, Passchier J, Berger MY. Prognosis of chronic or recurrent abdominal pain in children. J Pediatr Gastroenterol Nutr. 2008;47(3):316-326.

11. Lindley KJ, Glaser D, Milla PJ. Consumerism in healthcare can be detrimental to child health: lessons from children with functional abdominal pain. Arch Dis Child. 2005;90(4):335-337.

12. van Tilburg MA, Venepalli $N$, Ulshen $M$, Freeman $K L$, Levy $R$, Whitehead WE. Parents' worries about recurrent abdominal pain in children. Gastroenterol Nurs. 2006;29(1):50-55, quiz 56-57.

13. Russo MW, Gaynes BN, Drossman DA. A national survey of practice patterns of gastroenterologists with comparison to the past two decades. J Clin Gastroenterol. 1999;29(4):339-343.

14. Westert GP, Schellevis FG, de Bakker DH, Groenewegen PP, Bensing JM, van der Zee J. Monitoring health inequalities through general practice: the Second Dutch National Survey of General Practice. Eur J Public Health. 2005;15(1):59-65. 
15. Lamberts H, Wood M, Hofmans-Okkes I. The International Classification of Primary Care. Oxford: Oxford University Press; 1987.

16. Norwegian Institute of Public Health. WHO Collaborating Centre for Drug Statistics Methodology. Guidelines for ATC Classification and DDD Assignment, 2010. 13th ed. Oslo, Norway: WHO; 2009. http:// www.whocc.no/filearchive/publications/2010guidelines.pdf.

17. Schellevis FG, Westert GP, de Bakker DH, Groenewegen PP. Tweede nationale studie naar ziekten en verrichtingen in de huisartspraktijk: vraagstellingen en methoden. Utrecht, NIVEL, Bilthoven RIVM; 2004.

18. van der Linden MW, Westert GP, de Bakker DH, Schellevis FG. Tweede Nationale Studie naar ziekten en verrichtingen in de huisartspraktijk. Klachten en aandoeningen in de bevolking en in de huisartspraktijk. Utrecht, NIVEL, Bilthoven, RIVM; 2004.

19. BEACH Program, AIHW General Practice Statistics and Classification Unit. Presentations of abdominal pain in Australian general practice. Aust Fam Physician. 2004;33(12):968-969.

20. Ramchandani PG, Hotopf M, Sandhu B, Stein A; ALSPAC Study Team. The epidemiology of recurrent abdominal pain from 2 to 6 years of age: results of a large, population-based study. Pediatrics. 2005;116(1):46-50.

21. Perquin CW, Hazebroek-Kampschreur AA, Hunfeld JA, et al. Pain in children and adolescents: a common experience. Pain. 2000;87(1):51-58.

22. Huertas-Ceballos A, Logan S, Bennett C, Macarthur C. Psychosocial interventions for recurrent abdominal pain (RAP) and irritable bowel syndrome (IBS) in childhood. Cochrane Database Syst Rev. 2008;(1):CD003014.

23. Hotopf M, Carr S, Mayou R, Wadsworth M, Wessely S. Why do children have chronic abdominal pain, and what happens to them when they grow up? Population based cohort study. BMJ. 1998;316(7139):1196-1200.

24. Di Lorenzo C, Colletti RB, Lehmann HP, et al; AAP Subcommittee; NASPGHAN Committee on Chronic Abdominal Pain. Chronic Abdominal Pain In Children: a Technical Report of the American Academy of Pediatrics and the North American Society for Pediatric Gastroenterology, Hepatology and Nutrition. J Pediatr Gastroenterol Nutr. 2005;40(3):249-261.

25. Rasquin A, Di Lorenzo C, Forbes D, et al. Childhood functional gastrointestinal disorders: child/adolescent. Gastroenterology. 2006;130(5):1527-1537.

26. Williams $N$, Jackson D, Lambert PC, Johnstone JM. Incidence of nonspecific abdominal pain in children during school term: population survey based on discharge diagnoses. BMJ. 1999;318(7196):1455.

27. Janssen HA, Borghouts JA, Muris JW, Metsemakers JF, Koes BW Knottnerus JA. Health status and management of chronic medically unexplained abdominal complaints in general practice. Br J Gen Pract. 2000;50(454):375-379.
28. Foets $M$, Cuperus J, Spreeuwenberg P, Verhaak $P$, van Engeland $H$ [Little recognition of mental problems in children by parents and family physicians] Weinig herkenning van psychische problemen bij kinderen door ouders en huisartsen. Ned Tijdschr Geneeskd. 1996;140(38):1907-1912.

29. Zwaanswijk M, Verhaak PF, van der Ende J, Bensing JM, Verhulst FC. Consultation for and identification of child and adolescent psychological problems in Dutch general practice. Fam Pract. 2005;22(5):498-506.

30. Costello EJ, Edelbrock C, Costello AJ, Dulcan MK, Burns BJ, Brent D. Psychopathology in pediatric primary care: the new hidden morbidity. Pediatrics. 1988;82(3 Pt 2):415-424.

31. Lane MM, Weidler EM, Czyzewski DI, Shulman RJ. Pain symptoms and stooling patterns do not drive diagnostic costs for children with functional abdominal pain and irritable bowel syndrome in primary or tertiary care. Pediatrics. 2009;123(3):758-764.

32. Vlieger AM, Blink M, Tromp E, Benninga MA. Use of complementary and alternative medicine by pediatric patients with functional and organic gastrointestinal diseases: results from a multicenter survey. Pediatrics. 2008;122(2):e446-e451.

33. Thompson EA, Bishop JL, Northstone K. The use of homeopathic products in childhood: data generated over 8.5 years from the Avon Longitudinal Study of Parents and Children (ALSPAC). J Altern Complement Med. 2010;16(1):69-79.

34. Huertas-Ceballos A, Logan S, Bennett C, Macarthur C. Pharmacological interventions for recurrent abdominal pain (RAP) and irritable bowel syndrome (IBS) in childhood. Cochrane Database Syst Rev. 2008;1(1):CD003017.

35. Quartero AO, Meineche-Schmidt V, Muris J, Rubin G, de Wit N. Bulking agents, antispasmodic and antidepressant medication for the treatment of irritable bowel syndrome. Cochrane Database Syst Rev. 2005;(2):CD003460.

36. Saps M, Youssef N, Miranda A, et al. Multicenter, randomized, placebo-controlled trial of amitriptyline in children with functional gastrointestinal disorders. Gastroenterology. 2009;137(4):1261-1269.

37. Khan NF, Harrison SE, Rose PW. Validity of diagnostic coding within the General Practice Research Database: a systematic review. Br J Gen Pract. 2010;60(572):e128-e136.

38. Spee LAA, van den Hurk APJM, van Leeuwen Y, et al. Childhood abdominal pain in primary care: design and patient selection of the HONEUR abdominal pain cohort. BMC Fam Pract. 2010;11:27. 